\title{
Automated technique for the estimation of fetal haemoglobin
}

\author{
S. R. BROOK, R. S. CRANE, R. G. HUNTSMAN, T. D. de C. MARSHALL, \\ D. S. MCLELLAN, AND M. J. SEMPLE \\ From the Department of Haematology, Lambeth and St Thomas' Hospitals, London, and the \\ Department of Epidemiology and Medical Statistics, London School of Hygiene and Tropical Medicine
}

SYNOPSIS An automated alkali denaturation technique which measures fetal haemoglobin is described. This method offers greater speed and a lower standard deviation than comparable manual methods.

In 1951 Singer, Chernoff, and Singer devised the 'oneminute alkali denaturation test' for fetal haemoglobin $(\mathrm{HbF})$ estimation. This test was later modified by prior conversion of haemoglobin to cyanmethaemoglobin (Betke, Marti, and Schlicht, 1959). Kristoffersen (1961) suggested that a greater sensitivity would be obtainable if the haemoglobin was estimated at the Soret band instead of at $540 \mathrm{~nm}$. Cabannes and Schmidt-Beurrier (1965) have described an automated technique in which the denatured adult haemoglobin was filtered off by material inserted into the tubing of the manifold. The automated method described here is based on the test of Singer et al (1951) and utilizes an improved filtration unit which was originally designed to automate the recognition of sickle-cell haemoglobin (Canning, Crane, Huntsman, and Yawson, 1972).

The alkali-resistant fraction of all blood samples was estimated manually by both the Singer and Betke techniques using, in each case, 540 and $420 \mathrm{~nm}$. When the automated technique was used, samples were examined both as a haemolysate and as a rapidly prepared lysed red cell suspension, all tests again being read at 540 and $420 \mathrm{~nm}$.

\section{Material and Methods}

SAMPLES

Venous blood was collected into sequestrene bottles from normal healthy individuals (12 samples); B thalassaemia minor patients (15 samples), including parents of children with $B$ thalassaemia major and patients diagnosed on abnormal blood

Received for publication 5 March 1974. films and raised haemoglobin $\mathrm{A}_{2}$; patients with sickle-cell haemoglobin $\mathrm{C}$ disease (three samples).

Standards were made using different mixtures of normal adult and cord bloods to give the requisite $\mathrm{Hb} \mathrm{F}$ concentrations.

PREPARATION OF SAMPLES

Standard lysates (10 g/100 $\mathrm{ml} \mathrm{Hb}$ concentration) were prepared (Lehmann and Ager, 1961).

'QUICK' LYSATES

Two $\mathrm{ml}$ of blood of known haemoglobin concentration was centrifuged for five $\mathrm{min}$ at $3000 \mathrm{rpm}$ $(1800 \mathrm{~g})$ in a graduated centrifuge tube. The plasma was removed with a Pasteur pipette, and distilled water was added carefully to the volume calculated to give a final haemoglobin concentration of $10 \mathrm{~g} / 100$ $\mathrm{ml}$. All samples were stored in liquid nitrogen after preparation.

\section{MANUAL METHODS}

As described by Singer et al (1951) and Betke et al (1959), reading all samples in both methods at 540 and $420 \mathrm{~nm}$, ie, each sample was estimated by four different techniques.

\section{AUTOANALYZER}

\section{Reagents}

10.083 molar sodium hydroxide.

2 Saturated ammonium sulphate containing concentrated (SG 1.18) hydrochloric acid $5 \mathrm{ml}$ per 21 .

\section{Filter paper reels}

Whatman grade 50 width $2.5 \mathrm{~cm}$. 
Apparatus

Technicon Autoanalyzer mark I consisting of (1) Technicon sampler II with 20 per hr 1 to 6 sample to wash ratio; (2) Technicon proportioning pump; (3) Technicon continuous filter but a modification of the standard filtering unit constructed in the manner described by Canning et al (1972); (4) Technicon colorimeter with $15 \mathrm{~mm}$ tubular flow-cell and two sets of standard interference filters $420 \mathrm{~nm}$ and $540 \mathrm{~nm}$, both of band width $\pm 9 \mathrm{~nm}$. The Soret band maxima of the filtrates by the Betke and Singer techniques were found to be 416 and $419 \mathrm{~nm}$, respectively; (5) manifold of which the flow diagram is shown in the figure. Standard tygon pump tubing is used. The polypropylene sample tube should be as short as possible. A short length of polypropylene sample tubing was also used for the filtrate line.

\section{EXPERIMENTAL DESIGN}

Hand analyses

The five standard samples were analysed six times and the $\mathbf{3 0}$ test samples once, each by four different techniques over 10 days, according to a statistical design which followed plan II, 1a (Cochran and Cox, 1957) with days as blocks. Estimates of error variance were calculated on the standards, correcting for timing effects, and were used to derive standard deviations.

\section{Machine analyses}

The samples were analysed in five batches: in each run, test samples (both standard and 'quick' lysates) and the five standard samples were analysed in duplicate, the batch order being at random. The machine was calibrated using values derived for the standards by Singer hand analysis at the appropriate wavelength.

\section{Results}

The ranges and means of results for the $\mathrm{HbF}$ concentration obtained in the three groups of samples by manual and automated techniques are shown in

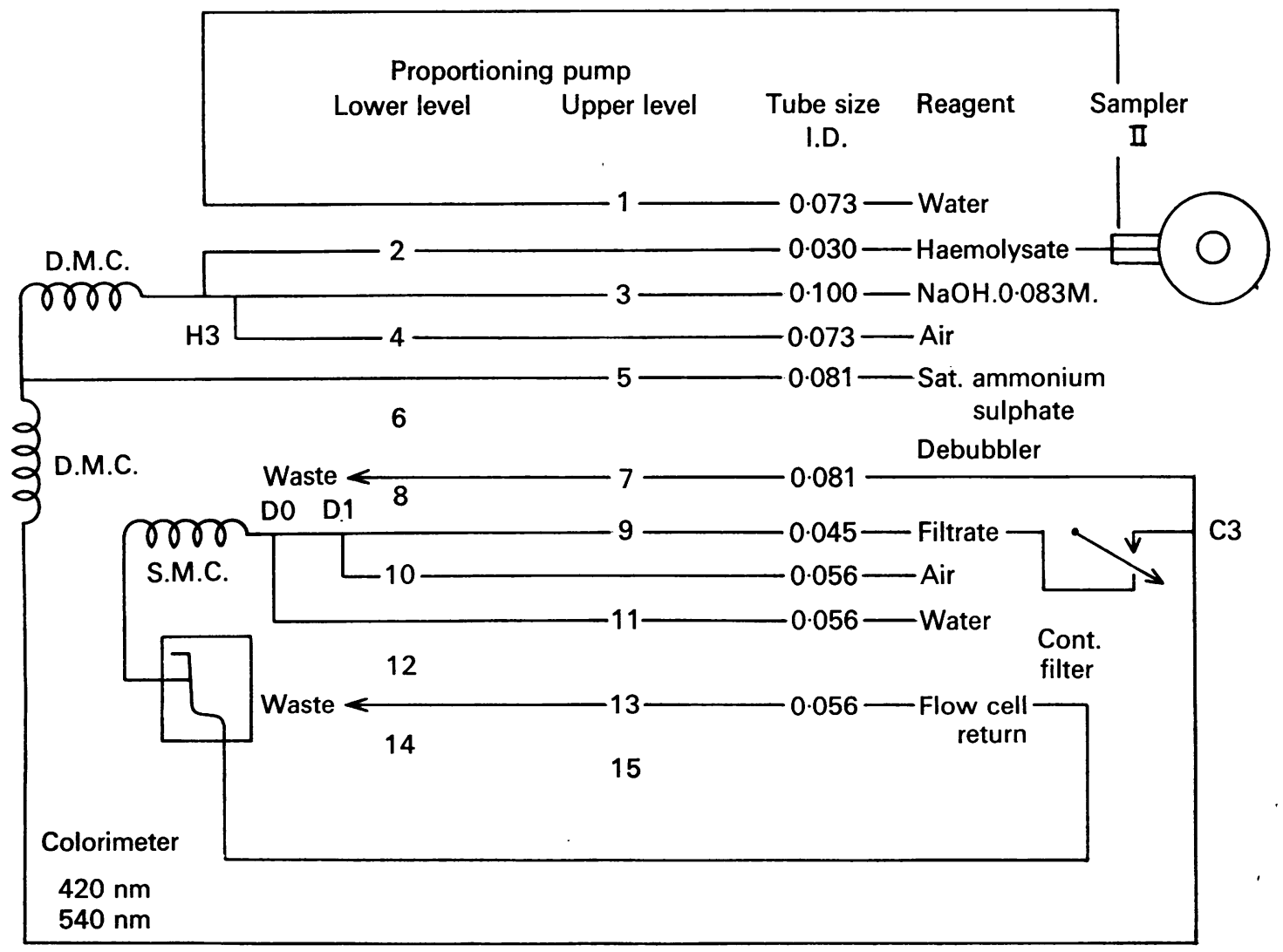

Fig Flow diagram for the estimation of fetal haemoglobin 


\begin{tabular}{|c|c|c|c|c|}
\hline & \multicolumn{2}{|l|}{ Manual Methods } & \multicolumn{2}{|l|}{ Machine Methods } \\
\hline & Singer & Betke & Standard Lysate & 'Quick' Lysate \\
\hline $\begin{array}{l}420 \mathrm{~nm} \\
\text { Normal } \\
\text { B Thalassaemia minor } \\
\text { Hb SC }\end{array}$ & $\begin{array}{l}0.72-1.55(0.99) \\
0.43-4.25(1.51) \\
0.40-1.15(0.67)\end{array}$ & $\begin{array}{l}0.94-1.74(1.15) \\
0.82-4.74(1.71) \\
0.60-1.55(0.96)\end{array}$ & $\begin{array}{l}0.49-1.40(0.80) \\
0.82-4.55(1.60) \\
1.27-1.40(1.36)\end{array}$ & $\begin{array}{l}0.67-1.84(1.08) \\
0.99-4.76(1.96) \\
1.06-1.64(1.34)\end{array}$ \\
\hline $\begin{array}{l}540 \mathrm{~nm} \\
\text { Normal } \\
\text { B Thalassaemia minor } \\
\text { Hb SC }\end{array}$ & $\begin{array}{l}0.52-1.36(0.87) \\
0.26-3.90(1.38) \\
0.37-0.84(0.54)\end{array}$ & $\begin{array}{l}0.76-1.66(1.08) \\
0.63-4.44(1.58) \\
0.65-1.53(0.97)\end{array}$ & $\begin{array}{l}0.62-1 \cdot 11(0.91) \\
0.95-3.77(1.48) \\
0.92-1.38(1.07)\end{array}$ & $\begin{array}{l}0.76-1.91(1.25) \\
1.2-4.39(1.89) \\
1.08-1.52(1.26)\end{array}$ \\
\hline
\end{tabular}

Table I Ranges and means of results of $\mathrm{Hb} F$ estimation

\begin{tabular}{llllll}
\hline & \multicolumn{2}{l}{ Manual Methods } & & \multicolumn{2}{l}{ Machine Methods } \\
\cline { 2 - 3 } \cline { 5 - 6 } & Singer & Setke & Standard Lysate & 'Quick' Lysate \\
\hline $420 \mathrm{~nm}$ & 0.273 & 0.194 & 0.133 & 0.115 & 0.288 \\
$540 \mathrm{~nm}$ & 0.256 & 0.199 & 0.192 & 0 \\
\hline
\end{tabular}

Table II Estimated standard deviations for each of the eight methods

table I. Table II shows the standard deviations for all the estimations.

The mean values for the two groups, normal and B thalassaemia minor in table $I$, were compared statistically. The test used allows for inequality in variance (Pearson and Hartley, 1970). This test showed no significant difference with determinations by hand methods, by either method at either wave- length. However, there was a significant difference between the two groups with machine estimations ( $P<0.01$ with each method at each wavelength). There were only three patients in the Hb SC group; as this group is so small, similar tests were not carried out.

In table III the correlation coefficients of the estimated values of the 30 samples are given for

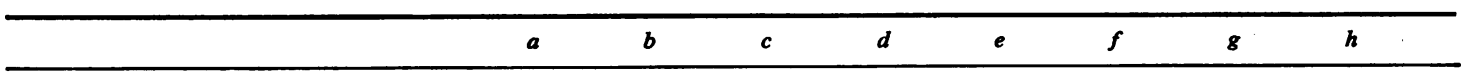

$420 \mathrm{~mm}$

Singer

Betke

Machine (standard)

Machine (quick)

$540 \mathrm{~nm}$

Singer

Betke

Machine (standard)

Machine (quick)

$\begin{array}{llll}\overline{0.97} & & & \\ 0.89 & 0.91 & \overline{0.97} & - \\ 0.91 & 0.93 & 0.97 & \\ & & & \\ 0.99 & 0.95 & 0.90 & 0.9 \\ 0.96 & 0.99 & 0.91 & 0.93 \\ 0.91 & 0.91 & 0.95 & 0.94 \\ 0.89 & 0.89 & 0.93 & 0.96\end{array}$

0.92
0.93
0.94
0.96

-1.94
0.90
0.89

Table III Correlation coefficients between pairs of estimates of the 30 test samples

\begin{tabular}{|c|c|c|c|c|c|c|c|c|c|}
\hline & & $a$ & $\boldsymbol{b}$ & $c$ & $d$ & $e$ & $f$ & 8 & $\boldsymbol{h}$ \\
\hline $\begin{array}{l}420 \mathrm{~mm} \\
\text { Singer } \\
\text { Betke } \\
\text { Machine (standard) } \\
\text { Machine (quick) }\end{array}$ & $\begin{array}{l}a \\
b \\
c \\
d\end{array}$ & $\begin{array}{l}-0.21 \\
-0.06 \\
-0.18\end{array}$ & $\begin{array}{r}-0.07 \\
-0.05\end{array}$ & -0.21 & - & & & & \\
\hline $\begin{array}{l}540 \mathrm{~mm} \\
\text { Singer } \\
\text { Betke } \\
\text { Machine (standard) } \\
\text { Machine (quick) }\end{array}$ & $\begin{array}{l}e \\
f \\
g \\
h\end{array}$ & $\begin{array}{l}0.34 \\
0.03 \\
0.60^{1} \\
0.38\end{array}$ & $\begin{array}{l}0.35 \\
0.39 \\
0.66 \\
0.47\end{array}$ & $\begin{array}{l}0.19 \\
0.08 \\
0.74 \\
0.50\end{array}$ & $\begin{array}{l}0.32 \\
0.22 \\
0.77 \\
0.67\end{array}$ & $\begin{array}{r}-0.14 \\
0.51 \\
0.27\end{array}$ & $\begin{array}{l}- \\
0.66 \\
0.39\end{array}$ & -0.36 & - \\
\hline
\end{tabular}

Table IV Correlation coefficients between differences and means of pairs of estimates of the 30 test samples 'Significant values $(P<0.005)$ in bold type 


\begin{tabular}{|c|c|c|c|c|c|c|c|}
\hline & & $a$ & $b$ & $c$ & $d$ & $e$ & $f$ \\
\hline $\begin{array}{l}420 \mathrm{~nm} \\
\text { Singer } \\
\text { Betke } \\
\text { Machine (standard) } \\
\text { Machine (quick) }\end{array}$ & $\begin{array}{l}a \\
b \\
c \\
d\end{array}$ & $\begin{array}{l}-4.76 \\
-0.52 \\
-5.03\end{array}$ & $\begin{array}{r}-2.48 \\
-2.34\end{array}$ & $-8 \cdot 02$ & - & & \\
\hline $\begin{array}{l}540 \mathrm{~mm} \\
\text { Singer } \\
\text { Betke }\end{array}$ & $\stackrel{e}{f}$ & $\begin{array}{r}5.40 \\
-2.33\end{array}$ & $\begin{array}{l}6 \cdot 77 \\
3 \cdot 70\end{array}$ & $\begin{array}{r}2.56 \\
-1.08\end{array}$ & $\begin{array}{l}7 \cdot 40 \\
3 \cdot 84\end{array}$ & $-4 \cdot 70$ & - \\
\hline
\end{tabular}

Table $\mathrm{V}$ Test statistical values ( $t$ at 29 df) for differences in pairs of estimates of the 30 test samples

'Significant values $(P<0.005)$ in bold type

each pair of techniques. These show a high level of agreement.

The extent of this agreement is examined further in tables IV and V. In table IV correlation coefficients of the difference between the two estimates and of the mean of the two are given for each pair of techniques. These will attain significance if the difference between estimates by two methods varies noticeably as the $\mathrm{Hb} F$ level increases. This happens only with the machine at $540 \mathrm{~nm}$ compared with other methods. An automated technique at this wavelength would not in any case have been chosen because of low sensitivity. In this respect, however, machine methods at $420 \mathrm{~nm}$ appear to be good.

In table $V$ results of a statistical test, the paired $t$ test, on the mean difference in estimates by two techniques are given, again for each pair of techniques. The automated technique at $540 \mathrm{~nm}$ is excluded because of the variation shown in table IV. The average separation of estimates by two methods is thereby assessed.

\section{Discussion}

The values of $\mathrm{HbF}$ in the 12 normal samples by the Singer manual method (see table I) at $540 \mathrm{~nm}$ correlates with the findings of Singer et al (1951) of a normal range of $0.5 \%$ to $1.7 \%$. The cyanmethaemoglobin method (Betke et al, 1959) at this wavelength gave normal values considerably greater than those quoted by these authors who regarded readings above $1.0 \%$ as clearly abnormal.

From table V, it can be seen that Singer results are lower than Betke results, at both wavelengths; either hand method gives higher readings at 420 $\mathrm{nm}$ compared with the same method at $540 \mathrm{~nm}$. The standard deviations attained by Pembrey, McWade, and Weatherall (1972), who used a modification of the Betke technique, reading at $415 \mathrm{~nm}$, are much lower than those obtained by our manual methods at either wavelength (table II). However, their standard deviation of 0.041 was obtained on 16 analyses of a single sample with a low $\mathrm{HbF}$ concentration (mean $0.465 \%$ ).
The automated technique not only offered greater speed (an output of approximately 20 per hour) but also gave standard deviations lower than those attained by using comparable manual techniques (table II). Machine readings at the longer wavelength $(540 \mathrm{~nm})$ tended to rise less rapidly with increase in percentage of $\mathrm{HbF}$ than do readings by manual methods; this phenomenon is not seen at $420 \mathrm{~nm}$. The automated technique gave raised fetal haemoglobin levels in only four out of 15 samples of $B$ thalassaemia minor and none of the samples of $\mathrm{Hb}$ SC disease. These four raised samples all gave recognizably high $\mathrm{HbF}$ levels by the manual techniques. Likewise the 11 samples of B thalassaemia minor and three samples of $\mathrm{Hb}$ SC disease with normal results by the automated technique gave manual results within the normal range.

Plasma absorbs light at $420 \mathrm{~nm}$ and thus increases the reading given by the alkali- resistant $\mathrm{Hb}$ fraction: this is mainly due to the protein and carotenoid content and is not significantly affected by high levels of bilirubin. A rapidly prepared lysate was therefore designed so that, after a single centrifugation, most of the plasma was removed before adjusting the haemoglobin concentration to $10 \mathrm{~g} / 100 \mathrm{ml}$ with distilled water. This preparation is also suitable for cellulose acetate electrophoresis as well as for the automated detection of $\mathrm{Hb} \mathrm{S}$ (Canning et al, 1972). It was therefore of interest that the automated $\mathrm{Hb}$ F technique described here apparently gave more satisfactory results with this preparation than with the time-consuming carefully prepared haemolysate. The results of $\mathrm{Hb} \mathrm{F}$ obtained with the 'quick' lysate method were a mean of $0.31 \%$ higher (see table $\mathrm{V}$ ); this could be allowed for with a correction factor or by accepting a higher normal range.

\section{References}

Betke, K., Marti, H. R., and Schlicht, I. (1959). Estimation of small percentages of foetal haemoglobin. Nature (Lond.), 184, 18771878.

Cabannes, R., and Schmidt-Beurrier, A. (1965). Depistage et dosage automatique de l'hemoglobine alcalino-resistante. Symposium Compagnie Technicon France, pp. 182-186.

Canning, D. M., Crane, R. S., Huntsman, R. G., and Yawson, G. I. 
484 S. R. Brook, R. S. Crane, R. G. Huntsman, T. D. de C. Marshall, D. S. McLellan, and M. J. Semple (1972). An automated screening technique for the detection of sickle-cell haemoglobin. J. clin. Path., 25, 330-334.

Cochran, W. G., and Cox, G. M. (1957). Experimental Designs, 2nd ed. Wiley, New York.

Kristoffersen, K. (1961). An improved method for the estimation of small quantities of alkali-resistant hemoglobin in blood. Scand. J. clin. Lab. Invest., 13, 402-409.

Lehmann, H., and Ager, J. A. M. (1961). Laboratory detection of abnormal haemoglobins. Association of Clinical Pathologists Broadsheet 33.

Pearson, E. S., and Hartley, H. O. (1970). Biometrika Tables for Statisticians. Cambridge University Press, London.

Pembrey, M. E., McWade, P., and Weatherall, D. J. (1972). Reliable routine estimation of small amounts of foetal haemoglobin by alkali denaturation. J. clin. Path., 25, 738-740.

Singer, K., Chernoff, A. I., and Singer, L. (1951). Studies on abnormal hemoglobins. I. Their demonstration in sickle cell anaemia and other hematologic disorders by means of alkali denaturation. Blood, 6, 413-428. 